\title{
The strategy of forming the research competence of students - architects by means of mathematics
}

\author{
Nail Tuktamyshov ${ }^{10000-0002-4679-0701]}$, and Tatyana Gorskaya*1[0000-0001-7136-8388] \\ ${ }^{1}$ Kazan State University of Architecture and Engineering, 420043 Kazan, Russia
}

\begin{abstract}
Formation of students' research competencies is an urgent and important task of universities, which fits into the implementation of the strategy of scientific and technological development of the Russian Federation. The paper discusses the impact of project-based learning technology of mathematics on the formation of research competencies of students-architects. The distinctive features of this work are: the use of design technology of teaching mathematics on the basis of an educational architectural project; identifying the criteria and indicators for the level of research competence of architecture students The paper presents the results of experiments confirming the effectiveness of the proposed technology. The perspectives of using project technology in architects' training are discussed.

Keywords. Research competence, mathematics as a means of formation, student's research activity, project method.
\end{abstract}

\section{Introduction}

As emphasized in many policy documents of the Russian government, science is a fundamental resource for the development of the economy, production and technology in modern conditions. Thus, the «Doctrine of Development of Russian Science», «National Doctrine of Education Development in Russia» and others proclaim the need to organize research activities, expand the freedom of scientific creativity, development of fundamental and applied developments. This requires the solution of a set of tasks: scientific support of research and teaching and research activities of students and teachers of universities; participation of higher education institutions in relevant regional, all-Russian and international programs; creating conditions for the effective development and improvement of the quality of scientific and pedagogical staff of higher education.

The formation of research competencies of students depends on solving current problems associated with the development of research (research) programs, and the degree of development of the model of formation of research competencies of graduates of higher education programs, based on the Unified Industry Qualifications Framework in research, development and education, including training of scientific personnel [1]. In this direction, the authors $[1,2]$ are working intensively on creating a model for developing the research competencies of the graduates of higher education programs. As part of this work, the methodological foundations and principles of creating the model have been defined. It should be noted that the National Qualifications System being formed in Russia still cannot

*Corresponding author: gorskaya0304@mail.ru 
determine the place of science-intensive, research competences [3]. All this leads to various misunderstandings. It should be said that in Europe there is a similar effort to define a qualification framework for the European Higher Education Area [4], which, in particular, notes that graduates of higher education «can apply their knowledge, understanding and problem-solving abilities in new or unfamiliar environments within broader (or interdisciplinary) contexts relevant to their field of study». In the European practice of higher education, the descriptions of qualification frameworks, including those describing research skills, are of a generalized, abstract nature and, as a rule, are not tied to the relevant scientific and professional fields. Foreign experience, apparently, was used in describing the competences presented in the FSES of higher education, which in the real practice of curriculum development in the areas manifested itself in a catastrophic reduction of hours in basic subjects, although the Council of Europe and the European Parliament had already drawn up a list of key competences which young Europeans should have: «the ability to communicate in the native and foreign languages; mathematical competence and basic knowledge in science and technology; IT-literacy». The aim of the work is to study the influence of project technology of teaching mathematics on the formation of research competences of students-architects.

\section{Materials and methods}

The state standards set the development strategy for higher education, which consists, firstly, in strengthening the applied orientation of education, on the other hand, in focusing on interdisciplinary integration. The depth, content, potential, and success of the strategy is determined not only by the narrow professional focus, but also by the diversity of the subjects studied, as well as the wealth of methods, approaches, and tools that allow training a deeply educated and competitive specialist. It is obvious that the basic disciplines constitute the core that allows for large-scale breakthroughs in the professional field, and orientation only on short-term successful result can have a bad effect on the prospects of development and very negatively affect the formation of research competences. It is well known that significant discoveries of applied nature often occur as a consequence of breakthroughs in fundamental research. According to [5], the strategy is understood as a chain of causal goals. The strategic goal as the development of competence areas necessary for successful career and professional growth of a graduate implies the study of market conditions (external conditions) and internal components of training (number of subjects of training, sequence of their presentation, connection between subjects, teaching methods and their focus on formation of certain competences, etc.). These conditions (external and internal) are connected and can be assessed by the results (number of Olympiads won at different levels, competitions, graduates' projects implemented in practice, etc.).

It is obvious that the realization of the university strategy is to ensure the growth of graduates capable of creative and research work and in demand on the market (local, regional, global). It is clear that being in demand on the market implies the ability to produce not only narrowly-specialized operations that do not go beyond strictly defined tasks, but also to improve the existing sphere of competence. If a graduate wants to be effective in today's competitive world, he or she needs comprehensive information about the market opportunities in the field of architecture, internal processes in this field, trends, styles of contemporary architecture, as well as the consequences of his or her decisions. All this presupposes training aimed at universalism and directed from subject-centrism to educational areas in the construction of curricula and standards [6]. The direction that provides a breakthrough is associated with the creation of textbooks on metadisciplines, cross-cutting disciplines that glue together various disciplines with their content and lead to professional knowledge. One of such key disciplines of architectural and technical education is mathematics. 
Learning students can be roughly divided into two groups. The first group can initially include those students who need training in new strategic areas of competence of a high level. This group ensures the competitiveness of the university, its brand through the personal success of the students. These students strive to realize their goals, which often coincide with the strategic goals of the university, they are strongly motivated, interested in research activities. The other group of students is more interested in obtaining standard knowledge, skills, and abilities. One of the most important tasks of university education is to increase the share of the first group of students, to explain to the students the fact that today routine work is becoming more and more automated, and the share of tasks that require standard approaches from a person is decreasing.

The strategy in the field of higher education is to prepare a competitive specialist in the labor market. With the globalization of world economy, close world cooperation in production and construction, the globalization of learning takes place, so strategies for training specialists should be focused on training a specialist capable of working in world markets. This requires the development of future specialists' global competences, which imply knowledge of the subject (their profession) and understanding of problems in their field in the international dimension; the ability to analyze information sources from different parts of the world.

In July 2005 the General Assembly of the UIA adopted a revised version of the «UNESCO/UIA Charter on Architectural Education» [7, C. 12]. In the section of the «Charter» devoted to the development of curricula for architectural schools and methods of mastering the skills and abilities necessary for the architect, in particular, the following is written: «The following starting points should be laid down in the development of curricula:

- Development of creative competence in building technology with an emphasis on indepth knowledge of scientific disciplines and construction methods relevant to architecture.

- Developing research skills as an integral part of architectural teaching, both for students and faculty».

The above excerpt emphasizes the importance of research competencies and emphasizes the value of knowledge not directly related to architectural activities [8].

One of the first pedagogical works, which touched upon the problem of competences, is the research conducted by S.E. Shishova, V.A. Kalneya [9]. It defines competence as: "Competence is a general ability based on knowledge, experience, values, aptitudes, which are acquired through training. Competence is not reducible to either knowledge or skills» [9, P. 71-72]. However, competence is the ability to find the necessary knowledge and skills to solve the problem encountered. At the same time, the notion of «research competence» in pedagogy is interpreted ambiguously. There are two approaches to the definition of «research competence» according to the criterion of the basis chosen by the researchers for defining the concept. In the first approach, the definition is based on the basic concept of "competence» and in this context research competence is considered as one of the key competences (along with other key competences). The author [10] chose the system-dynamic theory of activity (R.Kh. Shakurov) as the methodological basis for identifying the essence of research competence, according to which the structure of research competence is considered as an interrelated set of value-oriented, project-creative, object-educational and control-correctional components.

Often in practical and scientific activities, in addition to the word competence, the word «competence» is used, by which we, like many other scientists, will understand «the quality of a person who has an education of a certain level, and manifested in the ability and willingness (based on the education received) to act effectively» [11].

The increasing role of new information and science, the inability to use standard methods in solving problems, the need to use basic knowledge and the embodiment of new and original strategies actualize the need to form and develop students' research skills. 
Research competence should be defined as a body of knowledge in a particular field, as well as the presence of research skills and the ability to apply this knowledge and skills in real concrete activities. Obviously, research competence is formed as early as junior year, where they are introduced to the universal methods of the basic sciences.

Let us consider the formation of research competence of architecture students by means of mathematics. Mathematics, as the most important basic discipline, contributes to the development of such important characteristics of research activities as the ability to think logically, think critically, imagination, reasoning, intuition. Mathematics develops the ability to understand and analyze information, choose a variety of approaches and methods to solve problems, formulate the problem and appropriate hypotheses needed to solve it, and create research models of real-world objects and processes.

It is known [12] that there are different levels of formation of research competence. At the elementary level the student is in a well-defined framework of academic research: the stages of work are allocated, the terms of its implementation and options for demonstrating the results are determined; the options of research tasks, research plan (samples, algorithms), a set of information sources are offered; presentation and defense of the results occurs in the classroom. Elementary level involves the performance of research work under the guidance of a teacher. At the basic level students are offered a research task, but the main stages of research are carried out with a large degree of independence, the teacher can correct the work of students if necessary; the student is responsible for the timing of the research and chooses the way of presentation of the research results, although the results themselves may not yet be particularly original, but the research topic, the study itself is interesting and unconventional enough. The advanced level is defined by full independence in carrying out research activity: the student defines the research task independently and carries out research under the program developed independently; the student has steady interest in research activity; protection of the original ideas occurs at various student conferences, and results of work are presented in the form of theses or articles. The undergraduate level allows, as a rule, to form research competence at elementary or basic levels.

To form the research competence of architecture students in mathematics classes we used project-based learning technologies, because, from our point of view, they are closest to the method of architecture project creation («the method of the architect»), correspond to the specific activities of the architect and allow in approximation to the real activity of the architect to successfully form research competence.

In order to form research competence, we focused on the tasks of practical orientation, which allow you to see the use of mathematical knowledge in the upcoming professional activity and represent the project-technological tasks. Such tasks have a deep motivational and value-based nature, as well as provide an opportunity to generalize, draw conclusions, use information technology, present the results.

The research competence has the following components: motivational-target, cognitive, assessment-activity and communicative [13].

The motivational-target component of research competence implies personal interest and motivation of the student to study this mathematical discipline. The development of motivational-target component of student's research competence is especially manifested in the study of differential and integral calculus. Using real practical examples, possibly of an economic nature (data on interest rates in banks, the cost of production, the company's revenues), students calculate numerical characteristics. Motivation to succeed also plays an important role in the success of developing research competencies. Students with a high level of motivation are more active in seeking information, they are more determined, proactive, and more likely to show creativity and research skills.

The development of the cognitive component of students' research competence involves the development of the ability to work with original sources, various reference books, 
systematize the material, choose methods and ways of practical activity. This occurs during the study of all sections of the disciplines of the mathematical cycle, when students become familiar with basic concepts, definitions, theoretical facts and learn to choose from a variety of available conditions adequate methods of solving.

The assessment-activity component is formed when students perform practical operations, for example, learn to carry out the selection of objects from the general population, the choice of a geometric figure for the architectural object. As an assessment of the quality of learning, architecture students in mathematics were asked to perform a project involving a mathematical description followed by obtaining the geometric characteristics of structures, the external surfaces of which are both planes and curved surfaces, as well as surfaces of rotation. Thus students, based on their knowledge of: analytical geometry, vector algebra, graphs of functions of one and two variables, coordinate method and coordinate transformation, must describe mathematically the surfaces of structures, either known or designed by the students themselves. In addition, the task is to calculate the cost of materials and costs for the erection of objectsfacilities according to the given conditional costs of materials and works. To do this, it is necessary to obtain the metric characteristics of objects, namely lengths, areas, and volumes. For geometric figures with flat straight faces this question is solved according to geometric formulas known since school. However, if a flat body has curved boundaries, then the problem of finding area is reduced to integration over the boundaries of the flat body. Lengths of arcs of curves are also found by integrals. Volumes of spatial bodies are obtained by integrating functions of two variables describing the surface of the body.

The communicative component includes the student's ability to communicate, to present the material obtained, to convince partners of its correctness, etc.

All components of research competence act as criteria of its formation and express as a whole the attribute - research competence. Criteria include a set of basic indicators [14]. It should be noted that these criteria and indicators are in close unity and interrelation, thus forming an integral system and helping a student to orient in research activity, to achieve the goals. Criteria and corresponding indicators are given in Table 1.

Table 1. Criteria for Research Competence.

\begin{tabular}{|c|l|}
\hline Criteria & \multicolumn{1}{|c|}{ Scores } \\
\hline Motivation and purpose & Personal interest and motivation in getting results \\
\hline Cognitive & $\begin{array}{l}\text { Ability to discover and understand the theoretical basis of the problem, } \\
\text { determine the object and subject of the research, formulate a hypothesis, } \\
\text { navigate professional and related literature, the ability to understand } \\
\text { theoretically the problem, the ability to use scientific (mathematical) } \\
\text { knowledge in professional situations, the ability to connect parts of the } \\
\text { study and find relationships and dependencies between them }\end{array}$ \\
\hline Assessment-activity & $\begin{array}{l}\text { Ability to identify leading methods, techniques, technologies for } \\
\text { appropriate research, to analyze the work done to identify the most } \\
\text { important results, ability to present work in accordance with the } \\
\text { requirements for the research paper, ability to supplement and modify } \\
\text { the work as necessary in the process of research work, the ability to } \\
\text { interpret and formulate results, conclusions and recommendations }\end{array}$ \\
\hline Communicative & $\begin{array}{l}\text { Ability to justify the links between mathematical concepts and } \\
\text { architectural objects, the ability to present the results obtained, the } \\
\text { ability to organize effective communication, allowing for success in } \\
\text { the professional sphere of activity, the ability to use information } \\
\text { technology in order to communicate their results to the audience }\end{array}$ \\
\hline
\end{tabular}




\subsection{Experiment}

The pedagogical experiment was conducted in the period from 01.09.2018 to 01.03.2019 on the basis of KSASU. Two groups of the Faculty of Architecture were selected (30 students each in the control and experimental groups). The experiment consisted in the following. The experimental group, 7AP03, had to design a town consisting of buildings and constructions that are distinguished by novelty of design and ease of installation. The external surfaces of each building must be described by mathematical formulas. The result of the task should be presented in the form of a presentation. The control group was trained according to the traditional methodology, the quality of learning was assessed by traditional - control tests on the studied topics. Learning quality assessments were: for the experimental group - a presentation of the building with a description of surfaces in the form of mathematical formulas studied in the course program; for the control group - the results of the control on the topics of the course program.

To confirm the results of testing the effectiveness of the proposed pedagogical conditions for the development of research competencies, it was first necessary to conduct initial testing of both groups. Also for the adequacy of subsequent comparisons of both groups it was necessary to show their similarity before the beginning of the experiment. At the end of the experiment the final testing of the two groups was conducted according to the criteria described above. Comparison of test results at the end of the experiment in the control and experimental groups will determine the results of the impact of the pedagogical experiment on the experimental group.

Initial testing in mathematics in the control and experimental groups was conducted. Note that the levels (low, medium, high) of knowledge in mathematics were determined based on the number of solved test problems. To compare the two groups, we used $\chi^{\wedge} 2$ criterion, which showed their similarity, so further comparison of the selected groups will be correct (Fig. 1).

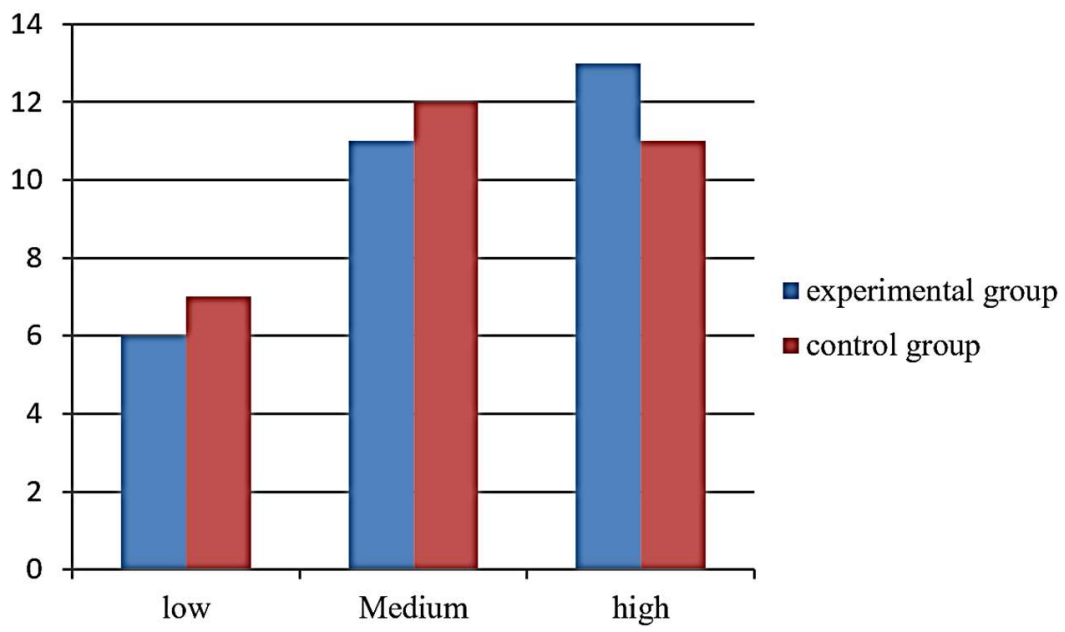

Fig. 1. Linear graph of the initial testing in mathematics in two groups.

It is plotted according to the testing data on mathematics, given in two groups of 30 people each, control and experimental in a pedagogical experiment on the formation of research competence.

The test developed by S.A. Mishin and successfully used by I.E. Idiatov [10] was chosen to reveal the level of research competence. We have modified and adapted this test to identify the research competence of students-architects. The test is a questionnaire of 100 questions, each of which must be answered «yes» or «no». A positive answer is evaluated by one point, 
and zero points are given for a negative answer. Below is a Table 2 that can be used to assess the level of research competence.

Table 2. Levels of research competence.

\begin{tabular}{|c|l|}
\hline Test Result & \multicolumn{1}{c|}{ Conclusion } \\
\hline 80 to 100 & $\begin{array}{l}\text { The subject's level is very high. He is able to conduct research independently, } \\
\text { monitor his level of competence. }\end{array}$ \\
\hline 60 to 80 & $\begin{array}{l}\text { The level of development of research competence is quite high. Is able to conduct } \\
\text { research with the help of the teacher, analyzes the product and process of the activity. }\end{array}$ \\
\hline 30 to 60 & $\begin{array}{l}\text { The test taker is clearly not new to research activities. At the same time, it is } \\
\text { recommended to conduct a more detailed analysis of deficiencies and to highlight } \\
\text { areas where work should be done to improve the level of research competence. }\end{array}$ \\
\hline 0 to 30 & Little or no research competence \\
\hline
\end{tabular}

Based on the test, initial research competence was measured in students in the control and experimental groups (Tables 3 and $3^{*}$ ).

Table 3. Results of the test on the level of research competence in the experimental group (at the beginning of the experiment, group 7AP03 of 30 people).

\begin{tabular}{|c|c|c|c|}
\hline $0-30$ & $31-60$ & $61-80$ & $81-100$ \\
\hline 6 & 15 & 9 & 0 \\
\hline
\end{tabular}

Table 3*. Results of the test on the level of research competence of the control group (at the beginning of the experiment, group 7AP02 of 30 people).

\begin{tabular}{|c|c|c|c|}
\hline $0-30$ & $31-60$ & $61-80$ & $81-100$ \\
\hline 7 & 13 & 10 & 0 \\
\hline
\end{tabular}

Testing conducted at the end of the experiment on the level of research competence showed the following results (Table 4 , Table $4^{*}$ ):

Table 4. Results of the test for the level of research competence (at the end of the experiment, the experimental group of 30 people).

\begin{tabular}{|c|c|c|c|}
\hline $0-30$ & $31-60$ & $61-80$ & $81-100$ \\
\hline 3 & 17 & 10 & 0 \\
\hline
\end{tabular}

Table 4*. Results of the test on the level of research competence of the control group (at the end of the semester, group 7AP02 of 30 people).

\begin{tabular}{|c|c|c|c|}
\hline $0-30$ & $31-60$ & $61-80$ & $81-100$ \\
\hline 5 & 15 & 10 & 0 \\
\hline
\end{tabular}

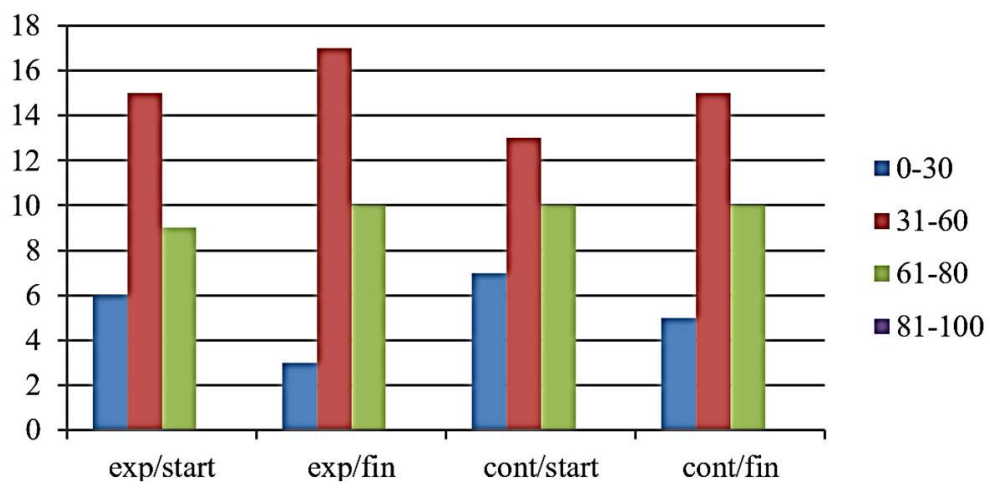

Fig. 2. Linear plot of the final comparison in the two groups. 
Here is a summary graph (Fig. 2) of the development of the level of research competence on the results of the experiment, which clearly shows an increase in the level of research competence. Constructed from data given in Tables 3 and $3^{*}, 4$ and $4^{*}$.

The average value of the final test shows that the criteria of the level of development of research competence of the experimental group increased during the experiment on average by about $9 \%$, in the control group - by $0.6 \%$.

\section{Results and discussion}

A new technology for teaching mathematics to architecture students was developed. Together with the teachers-architects developed a bank of educational architectural projects, in the development of which mathematical methods are effective; the criteria for assessing the research competence of students-architects were identified; experiments to test the effectiveness of the proposed project technology for teaching mathematics were conducted

New approaches in education have recently come to the fore, giving way to traditional approaches. The most productive from the point of view of learning are project technologies [15], as evidenced by scientific works on research on the effectiveness of learning [16]. Studies of such technologies have both cognitive and practical nature [17]. For example, the authors [18] suggest using blended learning, which contains traditional approaches and practice-oriented ones aimed at solving engineering problems, thereby involving students in solving real-world problems during training, which ensures more conscious learning of the subject. Thus, blended technologies are popular and are used by teachers all over the world [19].

For effective training of future specialists, formation of their professional skills, as well as for the formation of research competence, online courses, methodological recommendations, based, among other things, on the individualization of educational activities, are being developed. Digital technologies are actively used in educational activities now [20]. It is also noted that good mathematical training as a project activity apparatus $[20,21]$ allows the student to solve complex problems, thus becoming a sought-after specialist. The authors [22] note the positive impact of designing with the use of mathematical modeling on increasing students' interest in learning. Along with the technologies mentioned above, case technologies are also used, which are the most effective in the study of the modules of the science cycle [23]. The authors [24] use computer technology to evaluate the effectiveness of educational technologies, and determine the indexes of achievement [25]. Many authors also note that high-quality mathematical training enables better formation of research competence [26, 27]. The method of problem-based learning also contributes to the development of research skills [28]. The author [29] notes that the use of the method of project-based learning allows you to form an integrated mathematical representation. The technology proposed in the article does not contradict the technologies proposed by other researchers, but complements them, moreover, the research of many authors confirms the appropriateness of its use as effective in the formation of research competence. Computational methods are also widely used in the effectiveness assessment here, but unlike other technologies, an architectural design is proposed here, and the solution methods are mathematical. It is also appropriate to note that competitiveness in the labor market can be provided, including the ability to solve research problems. Therefore, qualitative training of specialists is very relevant both in our country and abroad [30]. In addition, it should also be noted that quality training cannot take place without continuous improvement in the professional and pedagogical competence of the teaching staff [31]. 


\section{Conclusions}

The project technology of teaching mathematics, as close as possible to the «method of the architect», whose characteristic feature is the development of an architectural learning project by mathematical means, is investigated and proposed in the paper. The paper analyzes the structure of research competence of architecture students and identifies the levels of research competence. The article confirms the effectiveness of the strategy of interdisciplinary approaches in teaching and the importance of studying mathematics in the course of architects' training. The results of the experiments that show the effectiveness of using the proposed technology are given. This work can be used to develop curricula in mathematics for architects.

\section{References}

1. E.V. Karavaeva, O.V. Vorobyova, V.P. Tyshkevich. Higher Education in Russia 27 (4), 33-47 (2018).

2. O.V. Vorobyeva, I.G. Teleshova. Higher education in Russia 27 (5), 74-86 (2018).

3. E.V. Karavaeva. Higher Education in Russia 12, 5-12 (2017).

4. Council of Europe. Symposium on Key Competences for Europe: Doc. DECS/ SC/SEC (96) 43, Berne, (1996).

5. R.S. Kaplan, D.P. Norton. Balanced Scorecard. From Strategy to Action, Moscow: ZAO «Olimp-Business», 210 (2003).

6. J. Moy. The impact of generic competencies on work place performance: Review of research, National Centre for Vocational Education Research, 50 (1999).

7. Accord ISA Agreement on Recommended International Standards of Professionalism in Architectural Practice, Union of Architects of Russia, 134 (2008).

8. Professional Standard: 10.008 Architect https://classinform.ru/profstandarty/10.008arhitektor.html.

9. S.E. Shishov. Monitoring the Quality of Education at School, Moscow: Pedagogical Society of Russia, 320 (1999).

10. I.E. Idiyatov. Formation of students' research competence in the process of problem-based learning. Kazan: Autoref. dissertation of candidate of pedagogical sciences, 27 (2016).

11. E.M. Schneider, Y.S. Dimitryuk. Modern problems of science and education 6, 144-144 (2017).

12. S.N. Panarina. Int. Sci. J. Innovation Science 8, 131-133 (2015).

13. G.K. Selevko. Public Education 4, 138-142 (2004).

14. E.V. Fes'kova. Constituent elements of research competence, Access mode: https://goo. gl/JiwzsX, (2004).

15. G. Flores-Fuentes, E.L. Juárez-Ruiz. Revista Electronica de Investigacion Educativa 19 (3), 71-91 (2017). DOI: 10.24320/redie.2017.19.3.721.

16. N.A. Orekhovskaya, A.A. Chistyakov, N.I. Kryukova, J.A. Krokhina, Y.V. Ospennikov, E.V. Makarova. European Journal of Science and Theology 15 (2), 67-77 (2019).

17. W.-L. Hsu, Y.-S. Chen, Y.-C. Shiau, H.-L. Liu, T.-Y. Chern. Edu. Sci. 9 (1), 65 (2019). DOI: $10.3390 /$ educsci9010065.

18. Y. Yang, Q. Zhang, B. Liu, L. Wang, X. Kong. International Journal of Information and Education Technology 9 (9), 618-622 (2019). DOI: 10.18178/ijiet.2019.9.9.1277.

19. A.I. Barham. European Journal of Educational Research 9 (1), 129-141 (2020). DOI: 10.12973/eu-jer.9.1.129.

20. L. Konnova, L. Lipagina, G. Postovalova, A. Rylov, I. Stepanyan. Edu. Sci. 9 (3), 182196 (2019). DOI: 10.3390/educsci9030182.

21. Y.I. Sanina, M.S. Artyukhina, N.G. Dendeberya, A.A. Savadova, I.V. Nasikan. IJRTE 8 (2), 3877-80 (2019). DOI: 10.35940/ijrte.B3078.078219. 
22. K.K. Naji, U. Ebead, A.K. Al-Ali, X. Du. Eurasia J. of Math., Sci. And Tech. Edu. 16 (8), em1867 (2020). DOI: 10.29333/ejmste/8291.

23. T. Yu. Gorskaya, I.I. Golovanova, R.S. Khammatova, A.E. Polichka, L.N. Romanchenko. EURASIA J. of Math., Sci. and Tech. Edu. 16 (11), em1900 (2020). DOI: $10.29333 /$ ejmste/8562.

24. K. Herbert, D. Demskoi, K. Cullis. Australasian J. of Edu. Tech. 35 (5), 153-167 (2019). DOI: $10.14742 /$ ajet.4539.

25. H.-Y. Tsai, C.-C. Chung, S.-J. Lou. Eurasia J. of Math., Sci.and Tech. Edu. 14 (1), 1532 (2018). DOI: 10.12973/ejmste/78019.

26. N.V. Telegina, S.E. Drovosekov, D.G. Vasbieva, V.L. Zakharova. Eurasia J. of Math., Sci. and Tech. Edu. 15 (8), 1738 (2019). DOI: 10.29333/ejmste/108439.

27. S. Rasslan, H. Arisha Haj Ihia, S. Haj-Yahia, A. Rasslan Sharif. Contemporary Math. and Sci. Edu. 1 (1), ep20004 (2020). DOI: 10.30935/ conmaths/8449.

28. R. Ratnasari, D. Safarini. TLS, Contemporary Math. and Sci. Edu. 1 (2), ep20008 (2020). DOI: $10.30935 /$ conmaths/8497.

29. V.A. Testov. Int. of Edu. 22 (3), 480-492 (2018). DOI: 10.15507/1991-9468.092.022. 201803.480-492.

30. N. Türk ,N. Kalayc1, H. Yamak. Universal J. of Edu. Res. 6 (6), 1286-1304 (2018). DOI: 10.13189/ujer.2018.060620.

31. R. Safin et al. IOP Conf. Ser.: Mater. Sci. Eng. 890, 012167 (2020). 